\title{
FEATURE The diversity of erosion control products and implications for wildlife entanglement
}

\author{
Krista J. Ward, Kasey L. Jobe, Nicholas C. Schiwitz, Daniel Saenz, and Christopher M. Schalk
}

I $\mathrm{n}$ the United States, roads are prominent across the landscape, negatively impacting wildlife and ecological processes via road mortality (Brady and Richardson 2017). The extensive roadway system in the United States requires consistent maintenance that results in soil erosion potential. For example, as of August of 2019 in Texas, there were 6,739 active roadway projects, with another 6,448 projects listed to begin within the next four years (Texas Department of Transportation 2019). Despite regulatory and mitigation efforts, soil erosion and stream sedimentation are known to occur at construction sites due to exposure of the soil to environmental factors that influence erosion rates (Kaufman 2000; Benik et al. 2003). At the conclusion of construction projects, the Texas Department of Transportation (TxDOT) mandates that erosion control products (ECPs) are deployed on unpacked soil to prevent soil erosion potential and to promote plant growth (Babcock and McLaughlin 2013; Texas Department of Transportation 2018a).

The TxDOT maintains an approved product list (APL) of all ECPs (ranging from mesh blankets to sprays and mulches) that can be used by contractors at the conclusion of a roadway construction project. To be placed on the APL, products must pass two performance standards: (1) protect the seedbed of an embankment or drainage channel from the loss of sediment during simulated rainfall or channel flow events, and (2) promote the establishment of warm-season, perennial vegetation (Texas Department of Transportation 2018a). However, there are currently no criteria that evaluate the risk of the ECPs to wildlife prior to their inclusion on the APL.

Erosion control blankets (ECBs) are deployed over large areas and are not regularly checked for entangled wildlife once installed (Kapfer and Paloski 2011; Ebert et al. 2019). Wildlife can become entangled in these ECBs (figure 1) often leading to their mortality (figure 2 ) due to

\section{Figure 1}

(a) A live western rat snake (Pantherophis obsoletus) encountered during a field survey of erosion control blankets at a completed Texas Department of Transportation construction site on April 30, 2018. The snake was entangled in multiple apertures of ECB S32 DB (2-layer erosion control blanket with fused, polypropylene netting) and had to be cut out of the mesh netting. (b) A close up of the body of the same snake where polypropylene mesh was embedded into the flesh of the snake.

(a)

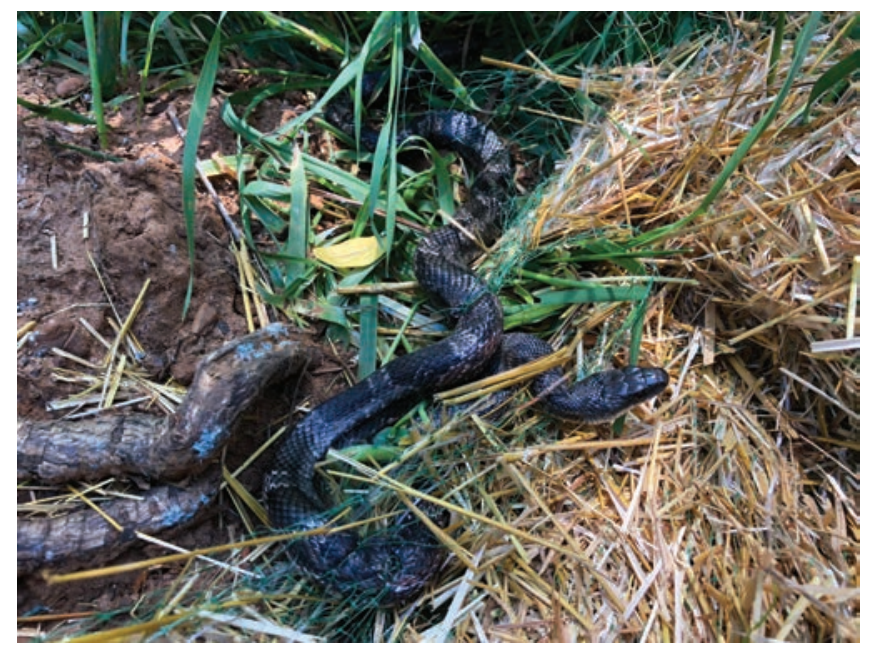

(b)

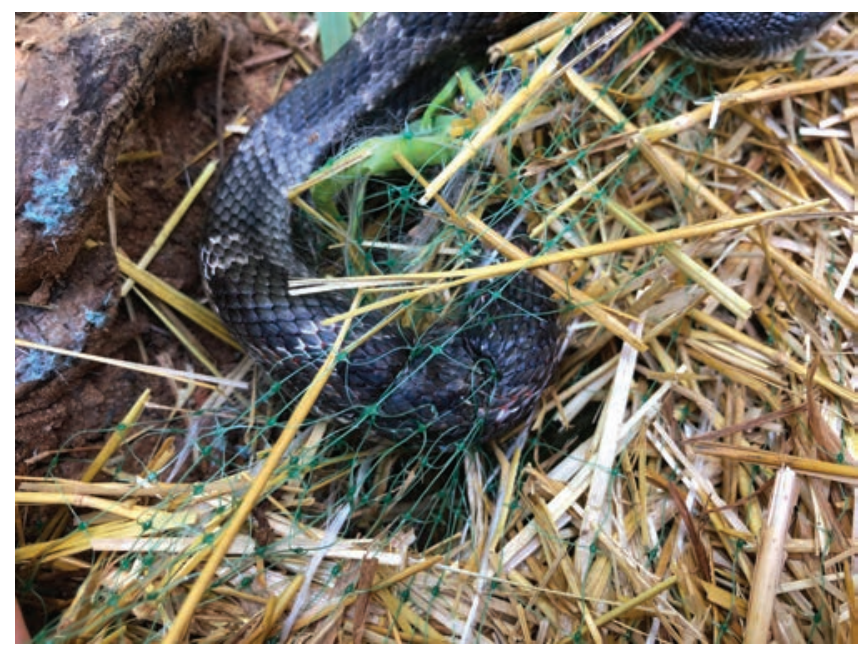

heat exposure, desiccation, increased vulnerability to predators, or deep lacerations caused by twisting in the mesh (Stuart et al. 2001; Barton and Kinkead 2005; Walley et al. 2005). Animals are at a higher risk of becoming entangled in ECBs with certain characteristics, specifically those with small, fused apertures and polypropylene mesh as these ECBs are unable to expand
Krista J. Ward and Kasey L. Jobe are undergraduate students in the Department of Biology, Stephen F. Austin State University, Nacogdoches, Texas. Nicholas C. Schiwitz is an undergraduate student and Christopher $\boldsymbol{M}$. Schalk is an assistant professor in the Arthur Temple College of Forestry and Agriculture, Stephen F. Austin State University, Nacogdoches, Texas. Daniel Saenz is a research wildlife biologist at the Southern Research Station, USDA Forest Service, Nacogdoches, Texas. 


\section{Figure 2}

A western rat snake (Pantherophis obsoletus) encountered during a field survey of erosion control blankets at a completed Texas Department of Transportation construction site on June 1, 2018. The snake was found deceased and entangled in multiple apertures of ECB S32 DB (2-layer erosion control blanket with fused, polypropylene netting).

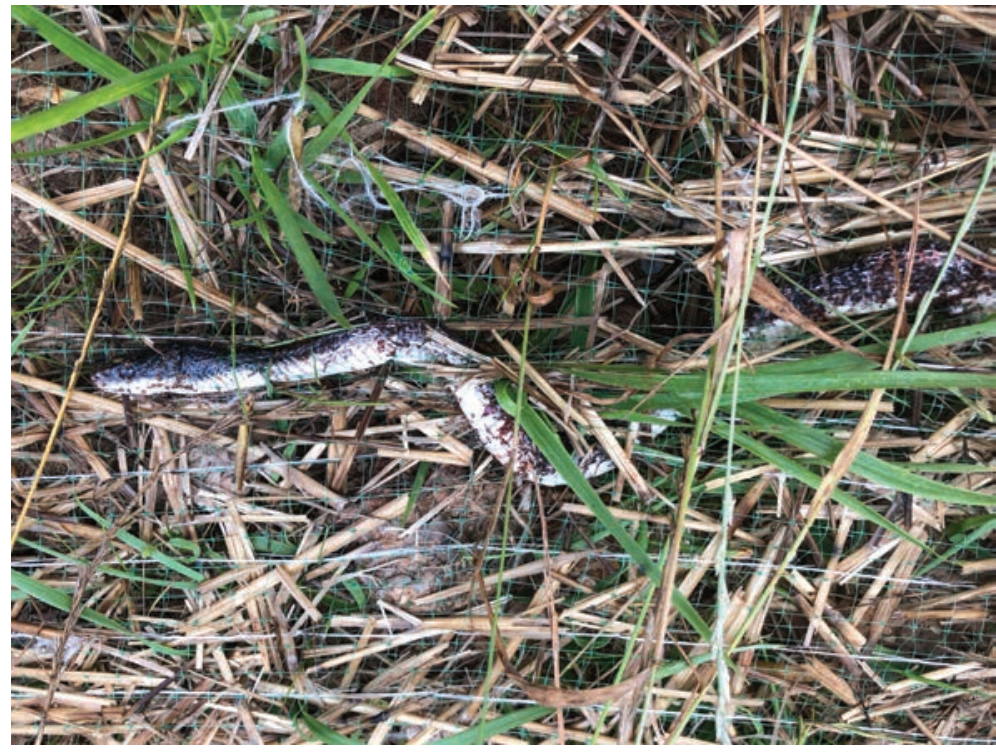

when the animal attempts to pass through (Stuart et al. 2001; Barton and Kinkead 2005; Ebert et al. 2019; Ward et al. 2020). In addition, the threat that these ECBs pose may be maintained over long time periods as some ECBs degrade slowly (one to three years or longer). According to Ebert et al. (2019), reptiles were frequently reported entangled in mesh products, with snakes being the most vulnerable to entanglement likely due to their morphology and certain life history traits that increase their encounter rates with these products (e.g., elongated body shape, active foraging strategies, engagement in mate searching behaviors, thermoregulatory behaviors) (Sullivan 1981; Bonnet et al. 1999; Barton and Kinkead 2005; Carfagno and Weatherhead 2008).

TxDOT's 2018 APL has 141 individual products that vary across multiple attributes (e.g., mesh size, matrix composition, permanency, etc.) specialized for installation on specific soils and slopes (table 1) (Texas Department of Transportation 2018b). The TxDOT groups products on the APL into two broad application classes: (1) terrestrial applications (e.g., ECBs) and (2) stream applications (e.g.,

\section{Table 1}

products are designated for use across multiple categories (i.e., multiple soil/ slope types) (View products and attributes at https://doi.org/10.2737/RDS-20200019). Given the large number of ECPs for a variety of slope/soil type scenarios and inconsistent availability of information on each ECP specification (due to information on fact sheets provided by different manufacturers), it is difficult for contractors or natural resource agencies to select an ECP that poses low risk of wildlife entanglement and fits their application needs. Understanding the diversity of ECPs as well as the frequency of known attributes correlated with wildlife entanglement (e.g., fixed mesh apertures) in the approved ECPs would be informative for contractors or natural resource agencies to select more "wildlife-friendly" products, if available.

\section{EVALUATION OF TEXAS DEPARTMENT OF TRANSPORTATION EROSION CONTROL PRODUCTS}

We reviewed the 141 ECPs on TxDOT's APL (Texas Department of Transportation 2018b) to determine (1) the frequency of ECPs with attributes known to pose a threat to wildlife, and (2) if wildlife-friendly alternatives are available. Specifically, for each ECP we attempted to classify the risk they pose to snakes by quantifying the following: (1) presence of mesh netting, (2) number of layers, (3) mesh intersection type, (4) mesh netting material, (5) aperture shape, (6) aperture

The number of mesh products and the number of meshless (i.e., "wildlife-friendly") products for slope/soil types for Class 1 (slope protection) and Class 2 (channel liners) on Texas Department of Transportation's 2018 approved product list (APL). The products may be used more than once between classes and slope/soil types. All meshless products are categorized as hydraulic sprays, and mesh products are categorized as mesh blankets or permanent mats.

\begin{tabular}{llll}
\hline APL category & & $\begin{array}{l}\text { Number of } \\
\text { mesh products }\end{array}$ & $\begin{array}{l}\text { Number of } \\
\text { meshless products }\end{array}$ \\
\hline Class 1 & Slope < 3:1; clay soil & 37 & 14 \\
Slope protection & Slope < 3:1; sandy soil & 41 & 12 \\
& Slope > 3:1; clay soil & 27 & 13 \\
& Slope > 3:1; sandy soil & 28 & 9 \\
\hline Class 2 & Stress range 0 to 96 Pa & 80 & 0 \\
Flexible channel liner & Stress range 0 to 192 Pa & 74 & 0 \\
& Stress range 0 to 287 Pa & 48 & 0 \\
& Stress range 0 to 383 Pa & 37 & 0
\end{tabular}


size, (7) time of degradation, (8) degradation type, (9) matrix constitution, and (10) application utilization (table 2). In addition to the aforementioned attributes known to be correlated with wildlife entanglement (i.e., aperture size, mesh netting material, and mesh intersection type), other attributes such as time to degradation, matrix constitution, and degradation type could provide insights to the longevity of a product that may pose a long term risk of entanglement in the environment. Also, those products that have broad applicability and can be used across multiple types of sites (e.g., those that can be installed across three or more types of slope/soil) may appear more frequently across the landscape and could result in an increased encounter rates by snakes and other wildlife.To quantify the attributes of each ECP, we reviewed product specification sheets from ECP company websites and consulted sales representatives.

We also explored the feasibility for natural resource managers and contractors to find ECP attributes to help inform them to select more wildlife-friendly ECPs. Therefore, we further classified ECP specification sheets into one of three categories: (1) complete (i.e., ECPs where information on all 10 attributes was found), (2) partial (i.e., ECPs where only some of the 10 attributes were found), and (3) none (i.e., ECPs where no information was found). For the ECPs with complete information, we constructed frequency histograms for each of the 10 attributes.

Our review of the 141 products on TxDOT's APL revealed $69.5 \%(n=98)$ of the ECPs had complete information on all 10 attributes, $14.9 \%(n=21)$ had partial information, and $15.6 \%(n=22)$ had no information (https://doi.org/10.2737/ RDS-2020-0019). Combining the products with complete information and products with partial information, we found 101 (85\%) had mesh present and 57 (47\%) had mesh with fused apertures (https://doi.org/10.2737/RDS-20200019).Across the 141 products on the APL, we could not determine the presence/ absence of mesh for 23 products $(16 \%)$ or fused apertures for 30 products $(21 \%)$ (https://doi.org/10.2737/RDS-20200019). Many products were discontinued,

\section{Table 2}

The list of primary traits that potentially influence snake entanglement and their defining characteristics. Each trait is separated into specific categories. The shortened name codes in parentheses of some trait categories correspond to the histograms in figure 3.

\begin{tabular}{|c|c|c|}
\hline Trait & Definition & Categories \\
\hline Presence of mesh netting & $\begin{array}{l}\text { Erosion control product } \\
\text { contains mesh netting }\end{array}$ & $\begin{array}{l}\text { Mesh netting present } \\
\text { Mesh netting absent }\end{array}$ \\
\hline Number of layers & $\begin{array}{l}\text { Number of layers of } \\
\text { mesh netting }\end{array}$ & $\begin{array}{l}0 \\
1 \\
2 \\
3\end{array}$ \\
\hline Mesh intersection type & $\begin{array}{l}\text { The type of joints at } \\
\text { mesh netting intersections }\end{array}$ & $\begin{array}{l}\text { Fused } \\
\text { Woven } \\
\text { Stitched } \\
\text { Not applicable }\end{array}$ \\
\hline Aperture shape & $\begin{array}{l}\text { The shape of the } \\
\text { mesh aperture }\end{array}$ & $\begin{array}{l}\text { Square } \\
\text { Rectangular } \\
\text { Not applicable } \\
\text { Triangle } \\
\text { Square and rectangle }\end{array}$ \\
\hline Mesh netting material & $\begin{array}{l}\text { Composition of erosion } \\
\text { control blanket netting }\end{array}$ & $\begin{array}{l}\text { Polypropylene (PO) } \\
\text { Koir } \\
\text { Jute } \\
\text { Nylon } \\
\text { Synthetic tackifier (SYT) } \\
\text { Netting absent (NEA) } \\
\text { Polyvinyl chloride (PVC) }\end{array}$ \\
\hline Aperture size & $\begin{array}{l}\text { The area of the mesh } \\
\text { aperture }\left(\mathrm{mm}^{2}\right)\end{array}$ & $\begin{array}{l}\text { Varying sizes } \\
0 \text { to } 500 \\
501 \text { to } 1,000 \\
1,001 \text { to } 1,500\end{array}$ \\
\hline Time to degradation & $\begin{array}{l}\text { Number of months until } \\
\text { product is fully degraded }\end{array}$ & $\begin{array}{l}0 \text { to } 6 \\
7 \text { to } 12 \\
13 \text { to } 24 \\
25 \text { to } 36 \\
37+\end{array}$ \\
\hline Application utilization & $\begin{array}{l}\text { The number of slope angles } \\
\text { and soil types a product } \\
\text { can be deployed on }\end{array}$ & $\begin{array}{l}\text { Specialized - One type of soil/slope } \\
\text { Moderate - Two types of soils/slopes } \\
\text { Broad - Three or more types of soils/slopes }\end{array}$ \\
\hline Matrix constitution & $\begin{array}{l}\text { The material between the } \\
\text { layers of mesh netting }\end{array}$ & $\begin{array}{l}\text { Coconut (CO) } \\
\text { Straw (ST) } \\
\text { Wood fibers (WF) } \\
\text { Mixture (MI) } \\
\text { Compost Material (CM) } \\
\text { Not applicable (NA) } \\
\text { Polypropylene (PO) } \\
\text { Excelsor (EX) } \\
\text { Flexterra HP-FGM (FL) } \\
\text { Plastic (PL) } \\
\text { Polyester (PY) } \\
\text { Acrylamide (AC) }\end{array}$ \\
\hline Degradation type & $\begin{array}{l}\text { The method of degradation } \\
\text { of the erosion control product }\end{array}$ & $\begin{array}{l}\text { Photodegradable (Photo) } \\
\text { Biodegradable (Bio) } \\
\text { Oxo-degradable (Oxo) } \\
\text { Multiple } \\
\text { Not degradable }\end{array}$ \\
\hline
\end{tabular}

renamed, or manufactured by companies no longer in operation, making specification sheets unobtainable $(n=22)$. Each of the four Class 1 (i.e., terrestrial application) slope/soil type product categories on the APL have at least one product with attributes not associated with risk of entanglement (i.e., mesh and/or fused apertures absent). All of the ECPs in the four Class 2 categories (i.e., stream applications) contained mesh with fused apertures (table 1). 
Of the 98 ECPs that had complete information, $86 \%$ contained mesh (figure 3a; https://doi.org/10.2737/ RDS-2020-0019) and 56\% contained two or more layers of mesh (figure $3 \mathrm{c}$ ). Furthermore, 55\% have fused apertures, $21 \%$ were stitched, $7 \%$ were woven, and 16\% lacked mesh (e.g., spray-on mulches) (figure 3e). The majority of ECBs with mesh were comprised of polypropylene (71\%; figure 3i), with most mesh apertures ranging from 0 to $500 \mathrm{~mm}$ (63\%; figure $3 \mathrm{~b})$. Straw was the most common material used in the matrix of ECPs $(24.5 \%$ of ECPs), followed by wood fibers (15.6\%), and polypropylene (14.7\%) (table 2 and figure $3 \mathrm{~h})$. The majority of ECPs were degradable $(65.7 \%)$, while the remaining ECPs were permanent (34.3\%; figure 3d). The degradable ECPs degraded via a combination of processes (e.g., a combination of photodegradable, biodegradable, or oxo-degradable; 16.7\%), while the majority (49\%) degraded by only one process (figure $3 \mathrm{j}$ ).

Attributes known to be correlated with wildlife entanglement (polypropylene mesh with small, fused apertures) were present in the majority of ECPs on TxDOT's APL. Additionally, one-third of these ECBs are not degradable and could potentially pose a long-term risk to wildlife. Meshless, spray-on mulches, or woven blankets listed on the APL may be safer alternatives as these products allow snakes to easily pass over or through them without risk of entanglement (Kapfer and Paloski 2011; Ebert et al. 2019). Kapfer and Paloski (2011) suggested that hydraulically applied ECPs (i.e., sprays) are the least likely to entangle snakes since they do not possess interconnected matrices. In an experiment testing the effectiveness of multiple mulch-based products with hydromulch sprays, Lee et al. (2018) found that the combination of mulch composition (e.g., straw) with hydromulch sprays was effective in reducing the turbidity of water runoff, suggesting these products are just as effective when compared to products with mesh under certain conditions. However, information on these attributes could not be found for all ECPs on the APL. It is unknown if there are additional wildlife-friendly alternatives as informa-

\section{Figure 3}

Percentage of erosion control products (ECPs) that yielded a complete review for all 10 attributes ( $n=98 \mathrm{ECPs}$ ) that exhibit (a) presence of mesh netting, (b) aperture size, (c) number of layers, (d) time to degradation, (e) mesh intersection type, (f) application utilization, (g) aperture shape, (h) matrix constitution, (i) mesh netting material, and (j) degradation type. The shortened name codes on the $x$-axis of graphs $h, i$, and j are listed in table 2.

(a)
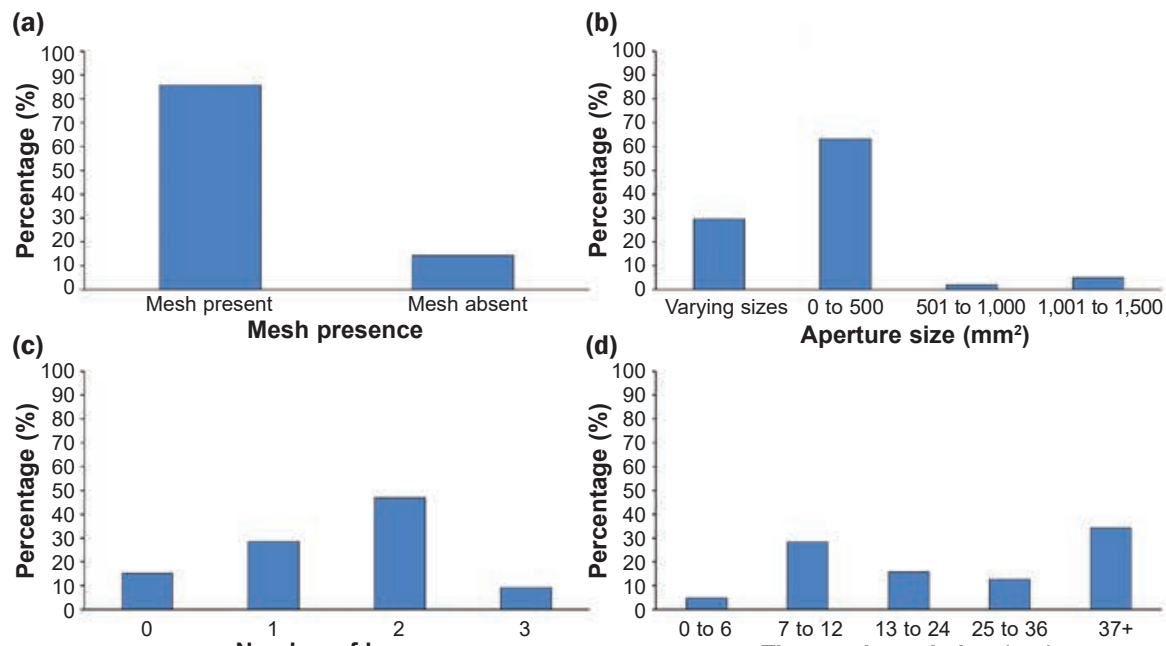

(e)
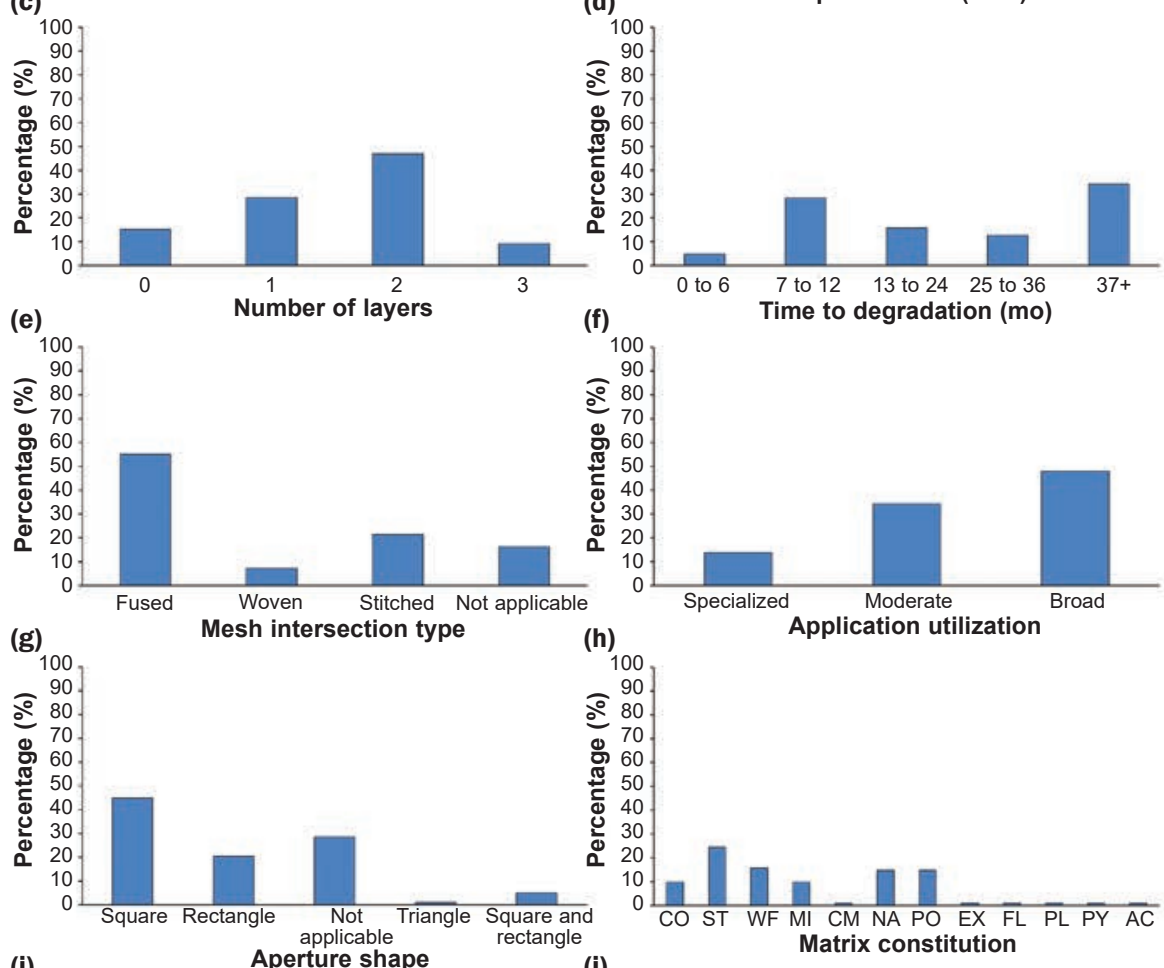

(h)

Application utilization
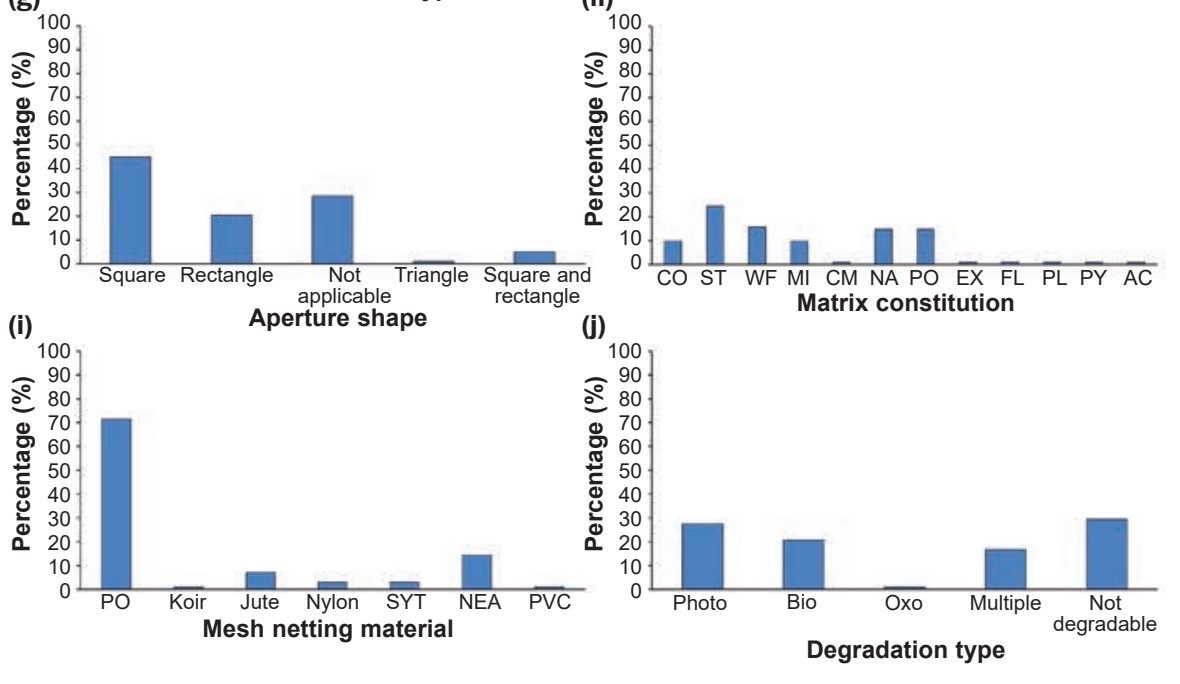

tion for all ECPs on the APL would enable natural resource agencies or contractors to make informed conservation decisions (Margules and Pressey 2000; Tulloch et al. 2015). However, it should also be noted that there have been no experimental studies (Ebert et al.2019) to determine the risks spray-on mulches pose to wildlife.

\section{ADDITIONAL EROSION CONTROL PRODUCT CONSIDERATIONS}

Many of the products that lacked information were either manufactured by companies 
no longer in operation or the specific product was no longer in production. If a product is discontinued or a company ceases operation, it is the manufacturer's responsibility to report the discontinued product/business so that their product(s) can be removed from the TxDOT APL (J. McFalls, personal communication, June 21, 2019). Many manufacturers failed to report the discontinuation of their products, resulting in the APL to continue to list products that are no longer in production and thus cannot be purchased by contractors. Also, some ECPs changed names, resulting in some products being listed twice on the APL under different product names. This lack of communication from the manufacturers creates challenges for natural resource agencies or contractors to select the optimal product to meet their project's objectives.

Cost is an important factor that impacts ECP selection (Fay et al. 2012; Sidhu et al. 2015). However, multiple factors affect the cost of erosion control materials, including product quantity, weight, and distance shipped, all of which are dependent on the extent and location of the project (Porch 2019). As a result, we did not factor cost into our ECP attribute evaluation. A contractor works within the limitations of the project's budget and will likely select a cheaper ECP that still meets the APL standards, but may not be wildlife-friendly. By knowing if a wildlife-friendly ECP costs more a priori, a contractor can incorporate these costs into the project's budget to overcome this constraint.

Regulations on ECPs vary widely between states, which suggests that the approved ECPs may differ across the United States. For example, Texas and Nebraska focus on promoting vegetation growth after a construction project is completed, while other states, such as California, focus on preserving existing vegetation during the construction project (CalTrans 2019; Nebraska Department of Transportation 2019; Texas Department of Transportation 2018a). Wisconsin provides a representative to answer questions regarding their APL, allowing contractors to obtain information regarding approved ECPs (Wisconsin Department of Transportation 2019). In Texas, individual TxDOT districts can further determine which ECPs are suitable for installation at local construction projects. For example, the Lufkin TxDOT district banned ECBs that contain polypropylene mesh (C. Adams, personal communication, August 19, 2019). This variability of regulations across states and local districts highlights the need for detailed reviews of the approved ECPs to determine the risks these products may pose to wildlife nationally.

The variation in state and district regulations, plus the extensive diversity of products approved in each state, can make it difficult to select an optimal product. Our evaluation highlights that the majority of approved ECPs have attributes known to be associated with wildlife entanglement. Additionally, improved communication, easier information access, and selection of products without mesh and apertures could be employed to minimize the risk they pose to wildlife. Our review of TxDOT's APL can be used as a guide to help contractors, state department of transportation districts, and other agencies make an informed decision on selecting ECPs that are the most wildlife-friendly while meeting their application needs.

\section{ACKNOWLEDGEMENTS}

We thank Connor Adams, a graduate student in the Arthur Temple College of Forestry and Agriculture, Stephen F. Austin State University, Nacogdoches, Texas; Cory Adams, a wildlife biologist in the Southern Research Station, USDA Forest Service, Nacogdoches, Texas; James Childress, a forestry technician in Nacogdoches, Texas; Sarah Ebert, an undergraduate student in the Department of Biology, Stephen F. Austin State University, Nacogdoches, Texas; Dylan Thompson, an undergraduate student in the Arthur Temple College of Forestry and Agriculture, Stephen F. Austin State University, Nacogdoches, Texas; Carmen Montaña, an assistant professor in the Department of Biology, Stephen F. Austin State University, Nacogdoches, Texas; and Laura Zebehazy, program leader in Texas Parks and Wildlife Department's Wildlife Habitat Assessment Program, Austin, Texas, for constructive comments and assistance with this project. We thank Jett McFalls, an assistant research scientist in the Soil and Erosion Control Lab, Texas A\&M Transportation Institute, Bryan, Texas, for providing information on the Texas Department of Transportation's Approved Product List and Sarah Fuller, an outreach coordinator in the Arthur Temple College of Forestry and Agriculture,
Stephen F.Austin State University, Nacogdoches, Texas, for public outreach and awareness. We also thank the Texas Department of Transportation for funding.

\section{REFERENCES}

Babcock, D.L., and R.A. McLaughlin. 2013. Erosion control effectiveness of straw, hydromulch, and polyacrylamide in a rainfall simulator. Journal of Soil and Water Conservation 68(3):221-227, doi:10.2489/jswc.68.3.221.

Barton, C., and K. Kinkead. 2005. Do erosion control and snakes mesh? Journal of Soil and Water Conservation 60(2):33-35.

Benik, S.R., B.N. Wilson, D.D. Biesboer, B. Hansen, and D. Stenlund. 2003. Evaluation of erosion control products using natural rainfall events. Journal of Soil and Water Conservation 58(2):98-105.

Bonnet, X., G. Naulleau, and R. Shine. 1999. The dangers of leaving home: Dispersal and mortality in snakes. Biological Conservation 89:39-50.

Brady, S.P., and J.L. Richardson. 2017. Road ecology: Shifting gears toward evolutionary perspectives. Frontiers in Ecology and the Environment 15:91-98.

CalTrans (California State Transportation Agency). 2018. Specification Standards. Sacramento, CA: State of California Department of Transportation. http://ppmoe.dot.ca.gov/hq/ esc/oe/construction_contract_standards/std_ specs/2018_StdSpecs/2018_StdSpecs.pdf.

Carfagno, G.L., and P.J.Weatherhead. 2008. Energetics and space use: Intraspecific and interspecific comparisons of movements and home ranges of two colubrid snakes. Journal of Animal Ecology 77:416-424.

Ebert, S.E., K.L. Jobe, C.M. Schalk, D. Saenz, C.K. Adams, and C.E. Comer. 2019. Correlates of snake entanglement in erosion control blankets. Wildlife Society Bulletin 43:231-237.

Fay, L., M. Akin, and X. Shi. 2012. Cost-effective and sustainable road slope stabilization and erosion control. Washington, DC: Transportation Research Board.

Kapfer,J.M., and R.A. Paloski. 2011. On the threat to snakes of mesh deployed for erosion control and wildlife exclusion. Herpetological Conservation and Biology 6:1-9.

Kaufman, M.M. 2000. Erosion control at construction sites:The science-policy gap. Environmental Management 26:89-97.

Lee, G., R.A. McLaughlin, K.D. Whitely, and V.K. Brown. 2018. Evaluation of seven mulch treatments for erosion control and vegetation establishment on steep slopes. Journal of Soil and 
Water Conservation 73(4):434-442, doi:10.2489/ jswc.73.4.434.

Margules, C.R., and R.L. Pressey. 2000. Systematic conservation planning. Nature 405:243-253.

Nebraska Department of Transportation. 2007. Approved Product List. Lincoln, NE: Nebraska Department of Roads. https://dot.nebraska.gov/ media/6969/eros-sed-prod-list.pdf.

Porch. 2019. Cost to Install Erosion Control Mesh Calculator. https://porch.com/project-cost/ cost-to-install-erosion-control-mesh.

Sidhu, R.S., M. Dougherty, W.C. Zech, and B. Guertal. 2015. Cost effectiveness of erosion control covers during vegetation establishment under simulated rainfall. Journal of Water Resource and Protection 7:119-129.

Stuart, J.N., M.L. Watson, T.L. Brown, and C. Eustice. 2001. Plastic netting: An entanglement hazard to snakes and other wildlife. Herpetological Review 32:162-163.

Sullivan, B.K. 1981. Observed differences in body temperature and associated behavior of four snake species. Journal of Herpetology 15:245-246.

Texas Department of Transportation. 2018a. Introduction. Austin, TX: Texas Department of Transportation. http://ftp.dot.state.tx.us/pub/ txdot-info/mnt/erosion/product_evaluation/ introduction.pdf.

Texas Department of Transportation. 2018b. Approved Products List. Austin, TX: Texas Department of Transportation. http://ftp.dot. state.tx.us/pub/txdot-info/mnt/erosion/product_evaluation/approved.pdf.

Texas Department of Transportation. 2019. Project Tracker. Austin, TX: Texas Department of Transportation. http://apps.dot.state.tx.us/ apps-cq/project_tracker/.

Tulloch, V.J., A.I. Tulloch, P. Visconti, B.S. Halpern, J.E. Watson, M.C. Evans, and S. Giakoumi. 2015. Why do we map threats? Linking threat mapping with actions to make better conservation decisions. Frontiers in Ecology and the Environment 13:91-99.

Walley, H.D., R.B. King, J.M. Ray, and J. Robinson. 2005. What should be done about erosion mesh netting and its destruction of herpetofauna. Journal of Kansas Herpetology 26-28.

Ward, K.J., K.L. Jobe, N.C. Schiwitz, D. Saenz, and C.M. Schalk. 2020. Risk of snake entanglement is affected by installation method of erosion control blankets. Journal of Fish and Wildlife Management 11(1):273-278. https://doi. org/10.3996/102019-JFWM-087.

Wisconsin Department of Transportation. 2019. Product Acceptability List. Madison, WI: Wisconsin Department of Transportation.
https://wisconsindot.gov/Documents/doingbus/eng-consultants/cnslt-rsrces/tools/pal/ pal-guide-4-30-2019.pdf. 